\title{
E-LEARNING ASSISTED DRAMATIZATION FOR COMMUNICATIVE LANGUAGE ABILITY AND COLLABORATIVE LEARNING
}

\author{
Young Mee Kim \\ Korea Science Academy of KAIST, Baekyang Kwanmoon-ro 105-47, Jin-gu, Busan, S. Korea
}

\begin{abstract}
This study explores the possibilities of developing English communicative ability and fostering collaborative learning through a web-assisted dramatization project. The study aims to present hands-on class management approaches for the dramatization project including class strategies and teaching materials. The action research is based on the context of secondary school learners who use English as a foreign language. The study involves the process of the project model that covers from planning to producing dramas, using a web-assisted Learning Management System. The follow-up surveys indicate that using the dramatization project in English learning facilitates effective and collaborative learning environment as well as improving communicative abilities. The study discusses the benefits and potentials of using dramatization as a team-based project in language education.
\end{abstract}

\section{KEYWORDS}

Learning Management System, Collaborative Learning, Communicative Ability, Project-Based Learning

\section{INTRODUCTION}

Language learning within a communicative curriculum is, therefore, most appropriately seen as communicative interaction involving all the participants in the learning and including the various materials resources. Breen and Candlin (1980) state that language learning may be seen as a process which grows out of the interaction between learners, teachers, texts and activities. The pedagogic rationale for project-based learning rests on the claim that they will help to develop learners' communicative skills and their linguistic development. Communication tasks are important for both fluency and accuracy (Brumfit 1984). They aid fluency by enabling learners to activate their linguistic knowledge for use and contribute to accuracy by enabling learners to discover new linguistic forms and also by increasing their control over already-acquired forms (Nobuyosh and Ellis 1993:203). Long and Crooks (1992) adopt tasks and projects as the unit of analysis, support a focus on form and aim to help students systematize and extend their knowledge of particular grammatical or lexical features.

\section{AIM}

The dramatization project with the support of web-based Learning Management System intends to achieve the following aims:

1) To develop English communicative ability through project-based learning

2) To enhance integrated language learning through combination of productive and receptive language skills

3) To cultivate collaborative learning environment through team work.

The project is designed to explore the possibilities of developing English communicative ability and fostering collaborative learning through conducting dramatization project. In addition, the study aims to present hands-on class management approaches for the dramatization project including class strategies and teaching materials. 


\subsection{Process}

The action research is based on the context of secondary school learners who use English as a foreign language. The study involves the process of the project model that covers from planning to producing dramas, using a web-based Learning Management System. Project guidelines and evaluation information were given to 116 students along with previous project samples. Twelve to sixteen students in 8 classes were grouped into four. Sixteen groups of three or four students conducted 15-minute dramatization group project together. Students started brainstorming together, exchanging ideas and opinions to write an outline after selecting chapters and roles of each member. Each group needed to submit a final script and perform acting in class for 15 minutes. Evaluation processes were followed at the end for feedback. The whole process continued and was completed for two weeks in the form of the round-tour method to maximize members' involvement and collaboration. The figure 1 shows the overview of the dramatization project in real classroom context. The figure 2 presents the whole process of the dramatization project. The process runs in parallel at the web-based Learning Management System as well as in the classroom.

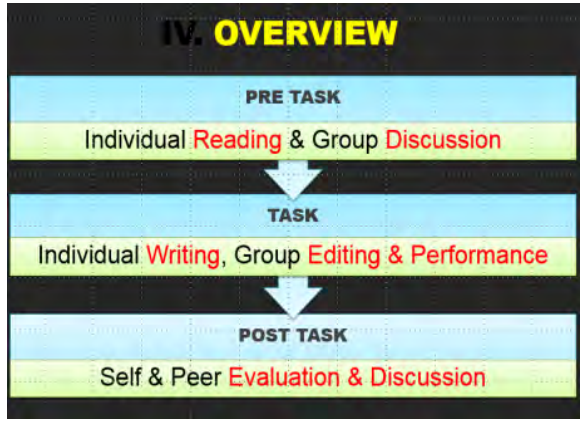

Figure 1. Overview of Project

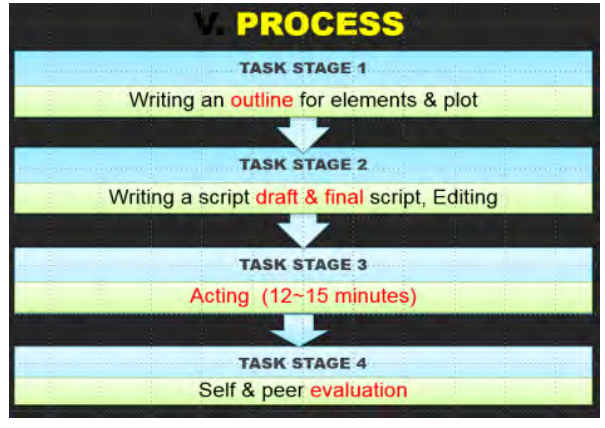

Figure 2. Process of Project

\subsection{Content and Materials}

Four parts of the main task stage are the core content of the dramatization project. The first part is to write an outline, including key elements and a plot for the project. After Students are introduced to the details of the project with specified guidelines, they are provided with two types of outline formats, descriptive and guided. One of students' main activities is to write a script for fifteen-minute acting. Students go through sessions of discussion and role taking and interact with a teacher to complete their final scripts in the form of draft script editing. The other main activity is the performance of fifteen-minute acting in class. During the performance other students conduct peer evaluation in the forms provided by a teacher. Right after the performance students evaluate themselves with a self-evaluation form. The figure 3 is the outline for students to fill out beforehand. The figure 4 is one of the various students' outcome of the outline.

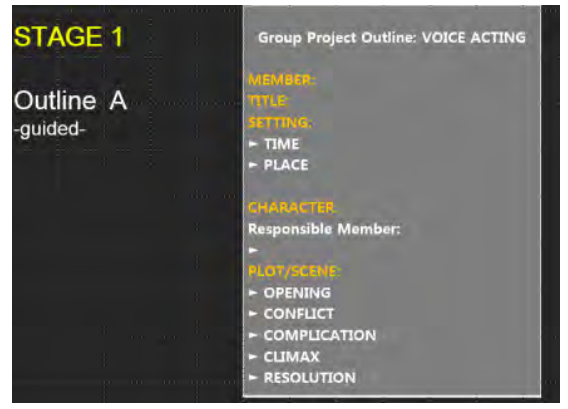

Figure 3. Outline of Project

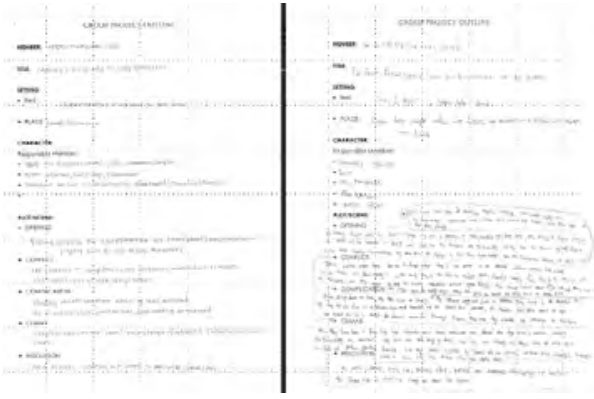

Figure 4. Outcome of Outline 


\subsection{Evaluation and Outcome}

At each part of the task stage, students are provided with relevant materials and appropriate outcome is expected to be produced. In the task stage one, documented specific guidelines for the whole project are given and students sign up for random grouping. In this stage, students' outcome is checked by the form of project outlines. For the stage of writing a script, teachers introduce script templates with samples of previous students' outlines and scripts. In the main performance and followed evaluation stage, teachers use formatted documents of peer evaluation and self-evaluation with the explanation of rationale of evaluation processes. Teachers provide each group with detailed feedback in the form of documented evaluation. The figure 5 and 6 are the teacher evaluation form and the outcome of peer evaluation. The figure 7 is the form of self-evaluation of the project and the figure 8 is the outcome of self-evaluation.

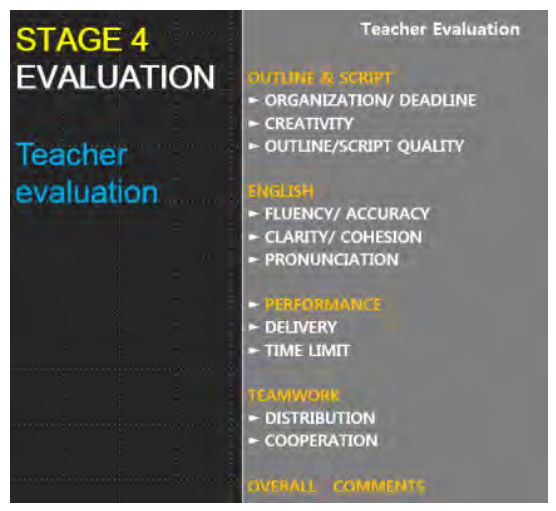

Figure 5. Teacher Evaluation of Project

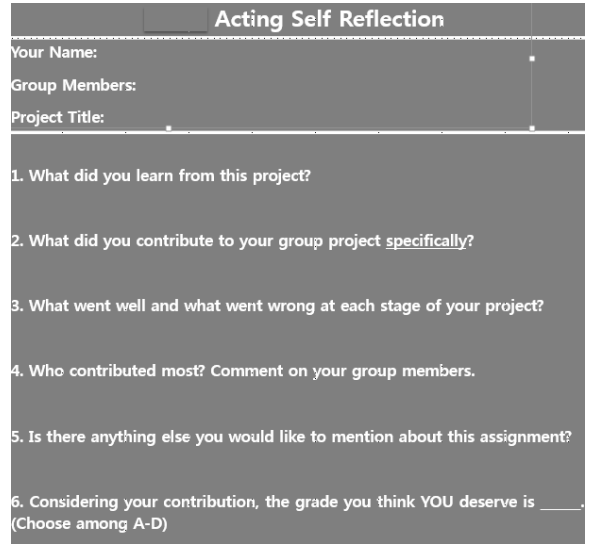

Figure 7. Self-evaluation of Project
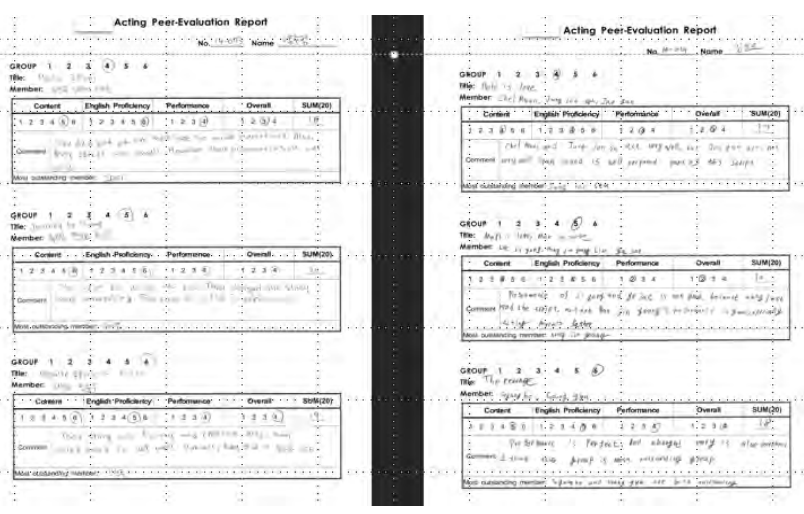

Figure 6. Outcome of Peer Evaluation

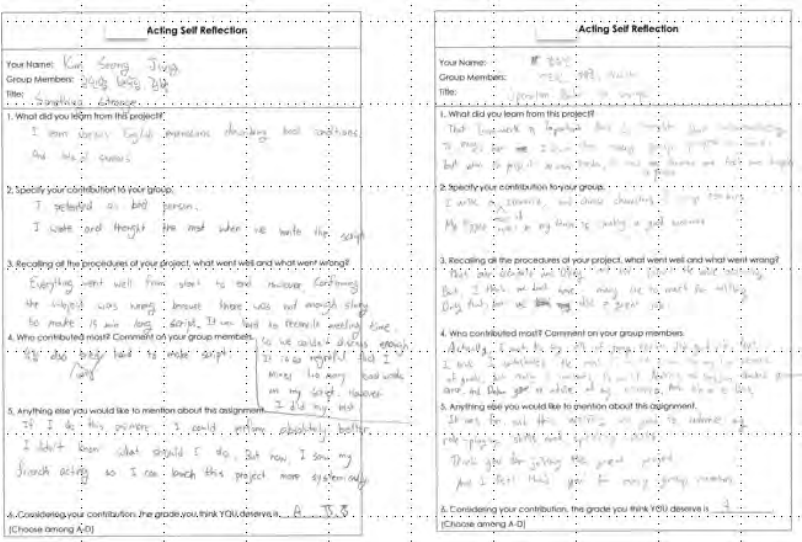

Figure 8. Outcome of Self-evaluation

\section{CONCLUSION}

The process of the dramatization project is focused on integrated language learning, covering speaking, listening, reading and writing. Collaborative learning environment is an additional merit for the project. The project is found to be useful for English communicative abilities with the main impetus of speaking ability. The purposely designed project materials and processes have positive influence on collaborative learning. The whole processes give an insight to educators for their decisions for communicative language learning and teaching strategies. The study discusses the benefits and potentials of using dramatization as a team-based project in language education for encouraging collaborative learning along with developing communicative skills. 


\section{ACKNOWLEDGEMENT}

This work was funded by the Ministry of Science and ICT.

\section{REFERENCES}

Brumfit, C. J. 1984. Communicative Methodology in Language Teaching. Cambridge: CUP.

Breen, M. Candlin, C. 1980. The essentials of a communicative curriculum in language teaching. Applied Linguistics 1(2), 89-110.

Nobuyosh, J. and Ellis, R. 1993. Focused communicative tasks and second language acquisition, ELT Journal 47(1), 203-10.

Long, M. H. and Crookes, G. 1992. Three approaches to task-based syllabus design, TESOL Quarterly 26(1), 27-55. 